\title{
Optimization of Solar-Driven of a small Absorption Air Conditioning System
}

\author{
Dr. A.S. Dawood / Assistant Professor H. A. Yousif/ M.sc \\ Dept. of Mechanical engineering / College of engineering / Mosul University
}

\begin{abstract}
This research deals with the optimum design of an absorption cooling system with cooling capacity of 2 ton refrigeratio driven by solar energy and using Lithium Bromide as absorbent and Water as refrigerant. The present system uses water for cooling the absorber, condenser and for heat transfer in the evaporator. A mathematical model is built to simulate a solar collector system and absorption system, in addition to design flat plate solar collector, f-chart method is used to find the optimum required solar collector area to air condition a space in the establishment with eight hour per working day. The coefficient of performance (COP) has been taken as a measurement to find the optimum internal operation conditions, by examining the performance of absorption system with varying temperatures to the generator, absorber, condenser, evaporator and effectiveness of a solution heat exchanger to obtain the optimum values of these operation conditions and also obtain maximum value of the COP. The result show that the collector area has a large effect on the actual useful heat gain and auxiliary heat to the system, and a collector area $26 \mathrm{~m}^{2}$ is enough to operate absorption system more than eight hours by using a water storage tank with a capacity of $1.5 \mathrm{~m}^{3}$ and depending on weather data of Mosul city. The results also show that the generator temperature had a great effect on the absorption and solar collector systems.
\end{abstract}

Keywords: absorption system, solar energy, water- lithium bromide solution, air conditioning, optimization.

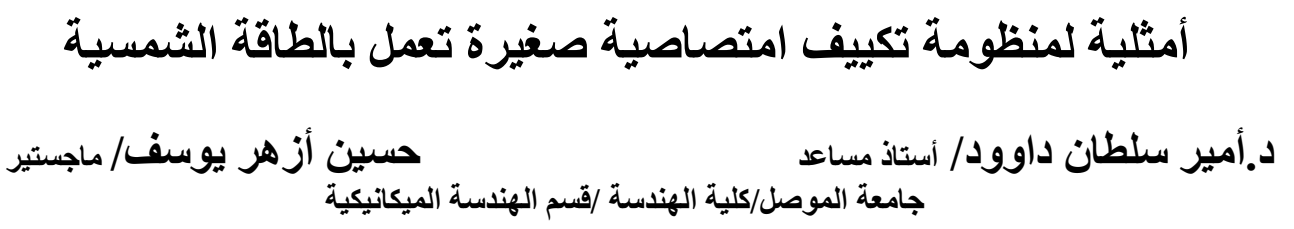

\section{الخلاصة تربة}

يتضمن البحث دراسة التصميم الأمثل لمنظومة تبريد امتصاصية سعة2 طن ت تعمل بالطاقة الثمسية

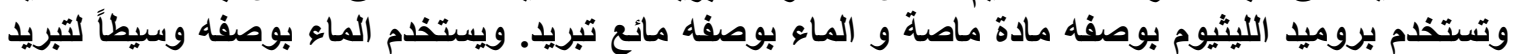

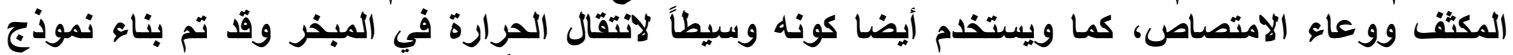

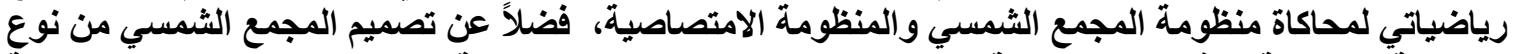

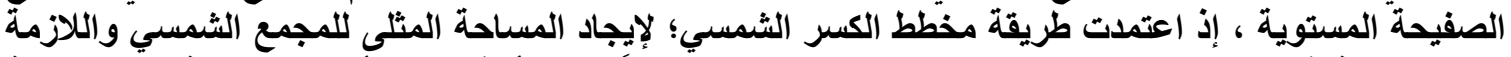

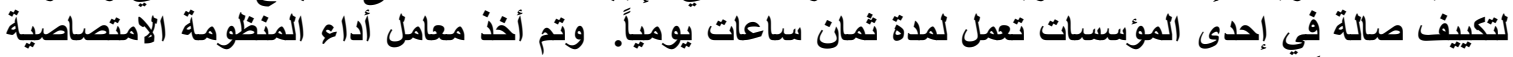

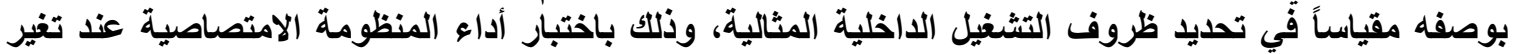

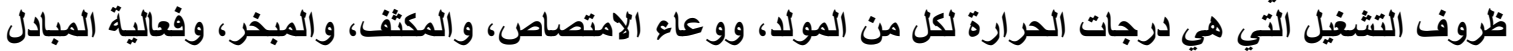

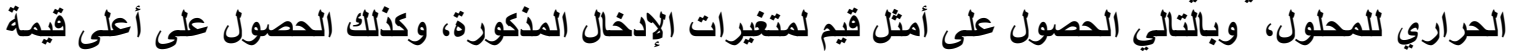

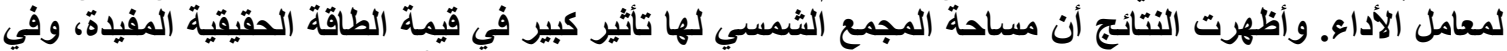

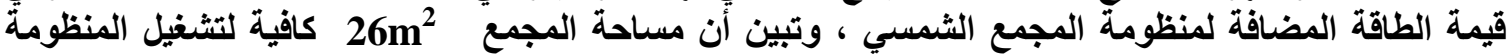

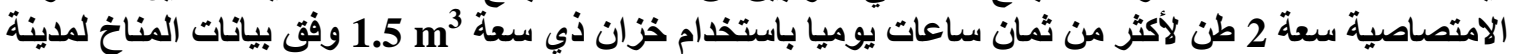

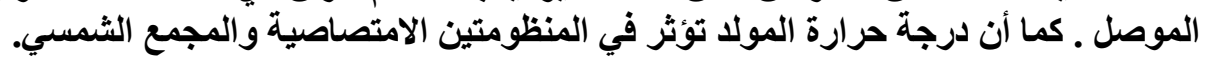

Received: $19-12-2011$

Accepted: $20-12$ - 2012 


\begin{tabular}{|c|c|c|c|c|}
\hline \multicolumn{5}{|c|}{ Symbols List } \\
\hline \multicolumn{3}{|c|}{ Nomenclature } & \multicolumn{2}{|r|}{ Subscripts } \\
\hline$A c$ & Collector surface area & $m^{2}$ & $1,2,3, .$. & $\begin{array}{l}\text { State at each point } \\
\text { in fig. } 4\end{array}$ \\
\hline$C p$ & Specific heat & $\mathrm{kJ} / \mathrm{kg} . \mathrm{K}$ & $\mathrm{a}$ & Absorber \\
\hline Cop & Coefficient of performance & ----- & aux & auxiliary \\
\hline$E$ & Effectiveness of heat exchanger & $\begin{array}{ll}----- \\
--1\end{array}$ & $c$ & Condenser \\
\hline$f$ & solar fraction & ------ & co & Cold \\
\hline$F^{\prime}$ & Collector efficiency factor & $\begin{array}{ll}----- \\
-\cdots\end{array}$ & $\mathrm{e}$ & Evaporator \\
\hline$F_{\mathrm{R}}$ & Heat removal factor & ----- & $g$ & Generator \\
\hline$h$ & Enthalpy & $\mathrm{kJ} / \mathrm{kg}$ & $i$ & inlet \\
\hline $\bar{H}_{T}$ & $\begin{array}{l}\text { Monthly average daily radiation } \\
\text { incident on the collector surface }\end{array}$ & $M J / m^{2} \cdot d a y$ & $h$ & Hot \\
\hline$I_{T}$ & $\begin{array}{l}\text { Hourly radiation on incident on } \\
\text { tilt angle. }\end{array}$ & $M J / m^{2} . h r$ & $h x$ & Heat exchanger \\
\hline$m^{o}$ & Mass flow rate. & $\mathrm{kg} / \mathrm{s}$ & $L$ & Heating load \\
\hline$N f$ & Number of days in month. & ----- & $o$ & exit \\
\hline$P$ & Pressure & $k P a$ & $s$ & Solution \\
\hline$Q$ & Heat exchanged & $W$ & $s t$ & Storage \\
\hline$S$ & Absorbtion solar energy & $M J / m^{2} \cdot h r$ & $u$ & Useful \\
\hline$T$ & temperature & $C^{\circ}$ & $h$ & Hot \\
\hline $\bar{T}_{a}$ & ambient temperature & $C^{\circ}$ & & \\
\hline $\bar{T}_{\text {ref }}$ & reference temperature & $C^{\circ}$ & & \\
\hline$L$ & Load & GJ & & \\
\hline$F_{L}$ & Monthly total heating load & GJ & & \\
\hline$U_{L}$ & $\begin{array}{l}\text { Collector overall losses } \\
\text { coefficient }\end{array}$ & $W / m^{2} \cdot K$ & & \\
\hline$X_{1}$ & Solution concentration & $\begin{array}{c}\mathrm{kg} \mathrm{LiBr} / \mathrm{kg} \\
\mathrm{Sol}\end{array}$ & & \\
\hline$X$ & Dimensionless group & ---- & & \\
\hline$Y$ & Dimensionless group & ---- & & \\
\hline$\beta$ & Tilt angle & Degree & & \\
\hline$\varnothing$ & Latitude angel & Degree & & \\
\hline$\eta$ & Efficiency $\%$ & ----- & & \\
\hline$\Delta t$ & $\begin{array}{l}\text { The total number of second in } \\
\text { the month }\end{array}$ & $S$ & & \\
\hline$(\tau \alpha)$ & $\begin{array}{l}\text { Transmittance- absorptance } \\
\text { products }\end{array}$ & & & \\
\hline
\end{tabular}




\section{Introduction}

The sun is one of the most important source of energy.itis a continued (renewable) and environment friendly and not a result of using fuel or other harmful products that leave residual such as a radioactive waste which results from using nuclear energy. Absorption systems are the most important applications of solar energy for refrigeration as using solar energy to supply the system's necessary heat, so the interest in this application is of great benefit; because the need for cooling to be in time with high intensity of solar radiation and temperature, and the more high intensity radiation increase the temperature of the hot fluid out of the solar collector and has been supplied to the absorption system, thus increasing the efficiency of the system, and because of the sunny climate of Iraq throughout the year, it is almost possible to use cooling systems operating by the principle of absorption widely by using solar energy.

Many researchers have shown Interest to studying the absorption cooling system power by solar energy, because of a wide range of reasons. Increasing energy costs, fear of depletion of conventional energy sources and environmental issues all added to this interest beside the fact of energy being a cornerstone of civilization and criteria of development. Theoretical study has been made to model and simulate of the solar absorption system utilization in space cooling of a small residential application according to the climatic conditions of Beirut, it is studying the relationship between the value of the solar annual fraction with the size of the water storage tank to different areas of the solar collector, and the results have shown that each ton of refrigeration required a minimum collector area of $23.3 \mathrm{~m}^{2}$, with optimal value of the water storage tank capacity that range $1000 \mathrm{~L}-1500 \mathrm{~L}$ for the system to operate solely on solar energy for about seven hours a day Ghaddar et al., [1]. And Hammad and Zurigat [2] developed absorption cooling system with a capacity of 1.5 ton operating with $14 \mathrm{~m}^{2}$ flat plate solar collector and containing five heat exchangers: the generator, the absorber, the condenser and the solution heat exchanger being of shell and tube type, the evaporator which is of the fin and tube types. The results are based on the observed operation of the unit during hours of sufficient solar irradiance in April and May, in Amman - Jordan, the results showed that the maximum value for the coefficient of performance obtained is equal to 0.85. Alva and Gonzalez [3] Accomplished the technical feasibility of using a compact air cooled solar-assisted absorption air conditioning system and uses lithium bromide -water as absorbent and refrigerant. A simulation that was carried out to find the optimal number of solar collector units and a comparison was made with an absorption air conditioning system that uses a cooling tower instead of air cooled components. The results showed that the optimal number of solar collector units, which the area of each unit of it is equal $2.42 \mathrm{~m}^{2}$, when the value of the fraction of solar is $100 \%$ for a period of daily run from $8 \mathrm{am}-17 \mathrm{pm}$, according to the weather data of Puerto Rico city is 19 units when carrying cooling $10.5 \mathrm{~kW}$, and 25 units when carrying cooling $14 \mathrm{~kW}$, and 32 units when carrying cooling $17 \mathrm{~kW}$, and the COP for the air cooled absorption machine decrease as the ambient temperature increases. While the cooling water one keeps COP almost constant. Another theoretical study model and simulate of an absorption solar cooling system according to the climatic conditions of Nicosia, Cyprus, Initially a system optimization was carried out in order to select the appropriate type of collector, the optimum size of storage tank, the optimum collector slope ,solar collectors area, and the optimum thermostat setting of the auxiliary boiler. 
The final optimized system consists of a $15 \mathrm{~m}^{2}$ compound of a parabolic collector tilted $30^{\circ}$ from the horizontal and a 600L hot water storage tank and the system operates with maximum performance when the auxiliary boiler thermostat is set at $87^{\circ} \mathrm{C}$ Florides et al., [4]. The present work, modeling and simulation that done for absorption cooling system with a capacity of 2 TR uses lithium bromide - water as absorbent and refrigerant and operating by flat plate solar collectors units to air conditions a space in the an establishment that works eight hours per day. To find the optimum required solar collector area and to find the optimum internal operation conditions that given the maximum value of the COP and to obtain the optimal design of each component of absorption system, depending on the weather data of Mosul city as shown in the figures (1),(2) and (3).

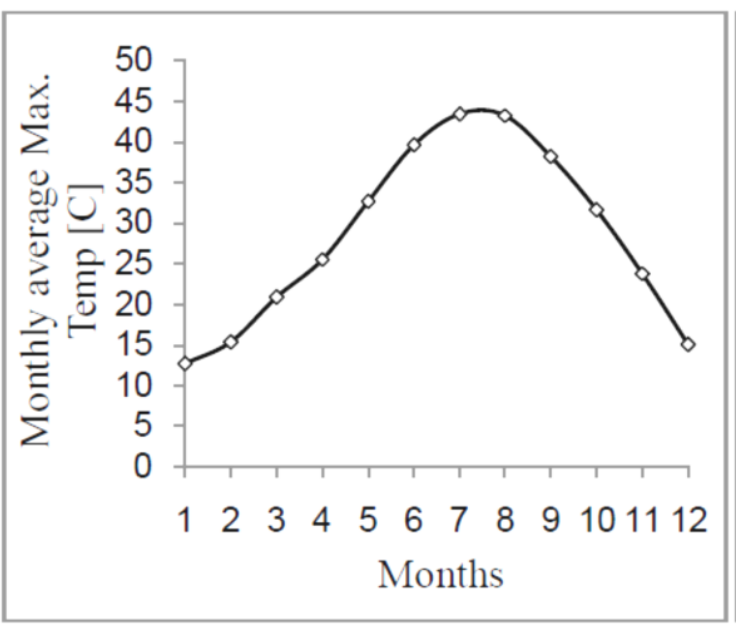

Fig (1) : Monthly average Maximum temperature from 2001 to 2006 .

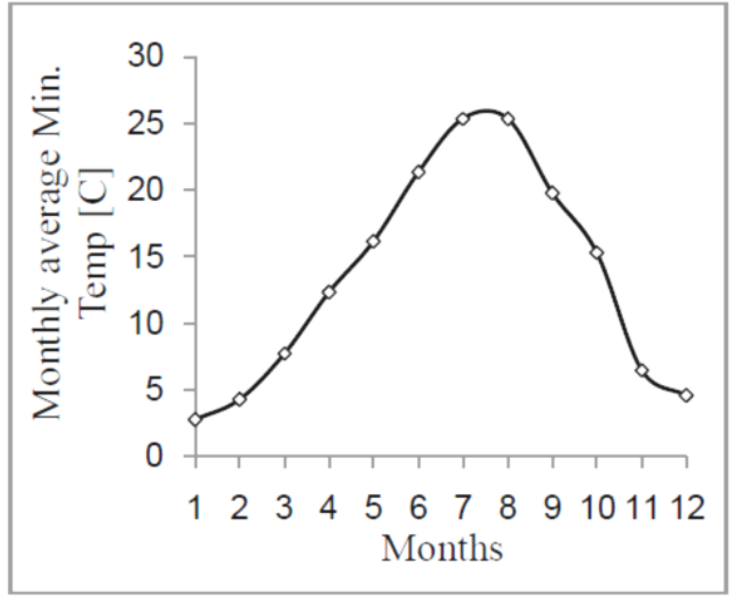

Fig (2) : Monthly average minimum temperature from 2001 to 2006 .

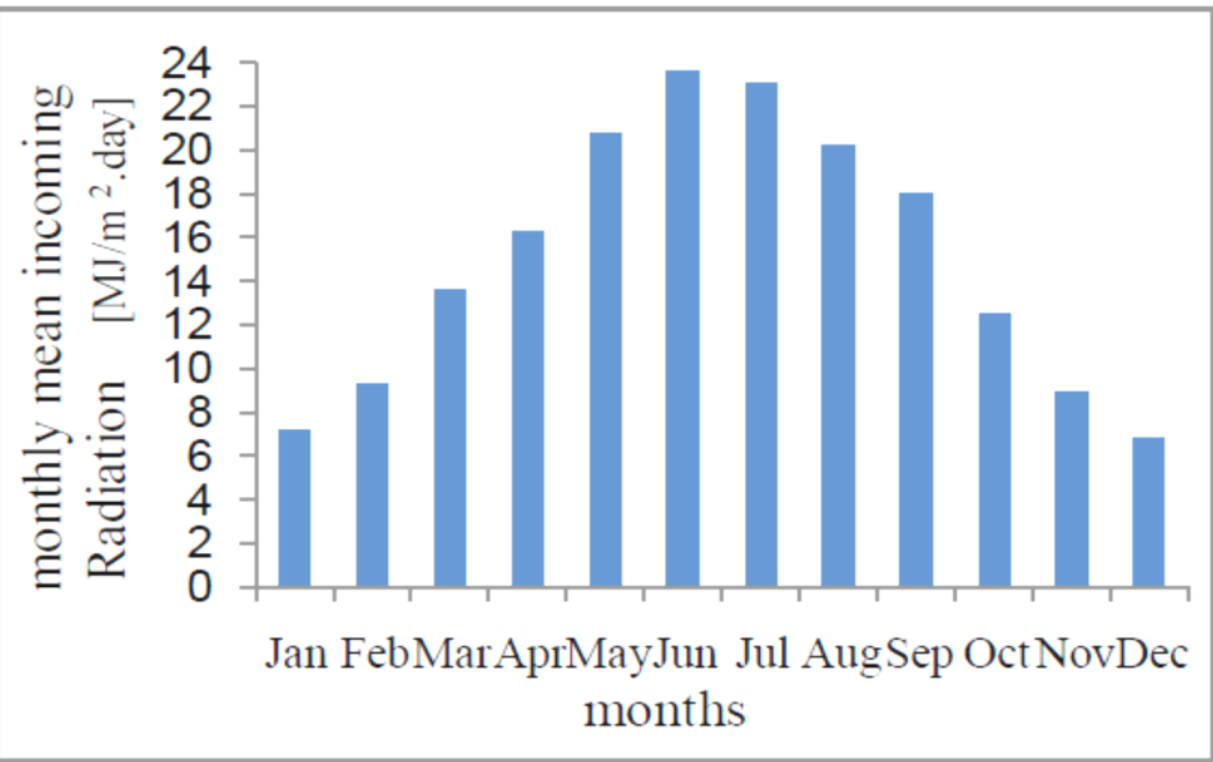

Fig (3) : Monthly average solar intensity on horizontal surface 


\section{System Description}

As shown in figure (4) the main components of a solar collector system and single effect lithium bromide-water absorption cooling system are solar collectors, water storage tank , auxiliary heater , generator, condenser, absorber, evaporator, solution heat exchanger, reduction valve, expansion valve and pumps.

The collector receives energy from sunlight. Then The solar energy is transferred to the storage tank and after that to the cooling system. In the absorption system, solar heat energy makes the vapor escapes from the solution in the generator, leaving a strong solution in it. The water vapor that generated is at high temperature and pressure. It is then passed to the condenser where heat is removed and the vapor cools down to form a liquid. To return the refrigerant, at a low pressure, it expands through an expansion valve. In the evaporator the refrigerant water is turned into vapor. The vapor then passes to the absorber. The strong remaining solution in the generator flows through the heat exchanger and the reducing valve to the absorber. In the absorber the lithium bromide absorbs the refrigerant that coming from the evaporator. As the quantity of lithium bromide that dissolves in the water increases, the temperature of the solution diminishes. Around the absorber refrigeration water is circulated to take away the freed energy from the lithium bromide in the solution and to keep up the absorber temperature as low as possible. The weak solution leaves the absorber and enters into the pump, where increases its pressure up to the generator's one then passes through the same heat exchanger to the generator again and the process is repeated.

The auxiliary heater is employed to elevate the temperature of a flow stream incoming to the generator (the auxiliary heater is activated only when the hot water temperature that required by the generator is not reach ed enough by using only solar energy).

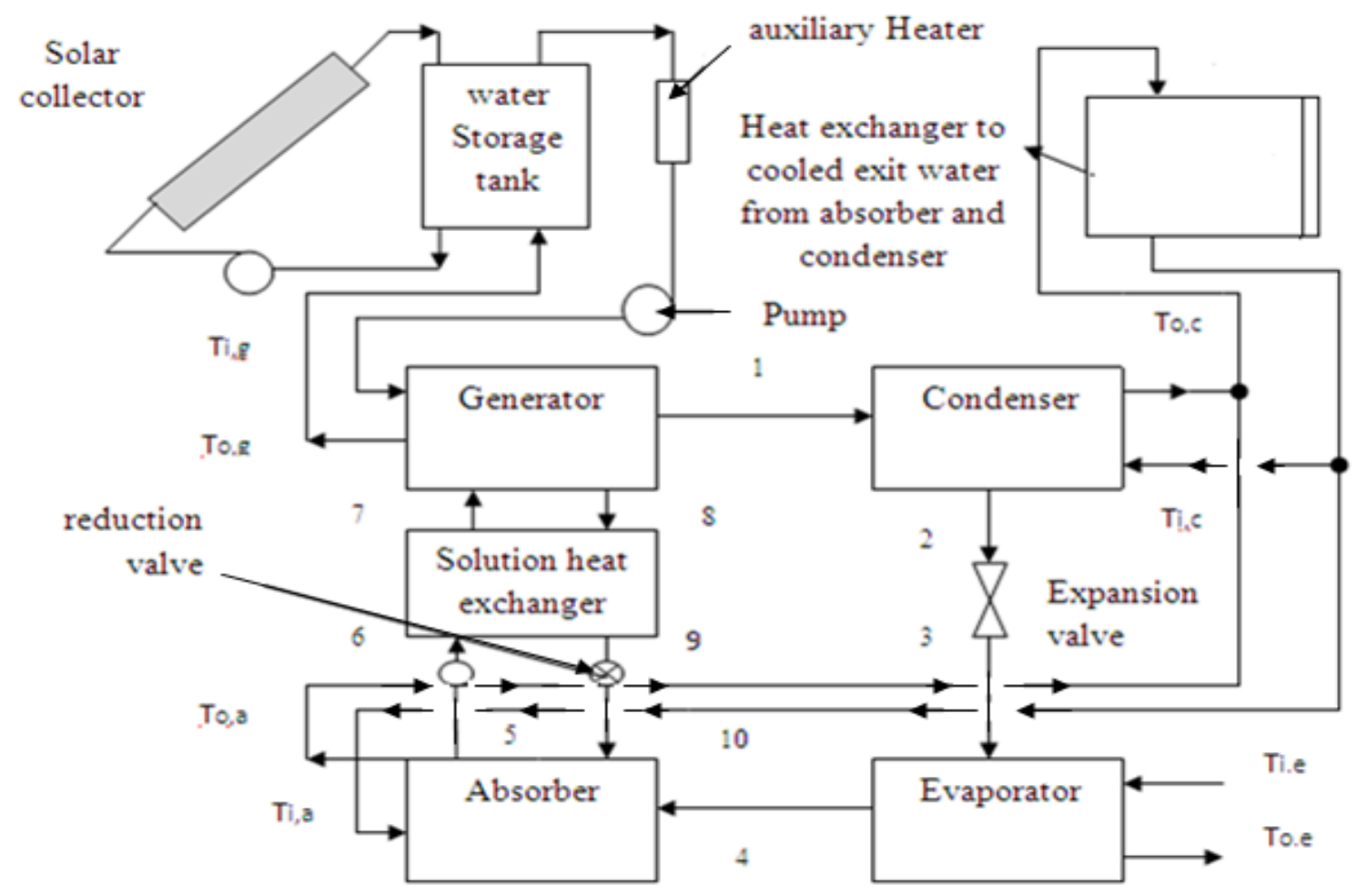

Fig(4): the schematic illustration of solar absorption system. 


\section{Modeling of Solar Collector System.}

The solar collector field is composed of several units of collectors, double glazing that collects and stores solar energy in a water storage tank. Each unit has an effective surface $2.185 \mathrm{~m}^{2}$. And at the beginning of the study a number of simplifying assumption can be made to lay the foundations without obscuring the basic physical situation. These assumptions are as follows [5]:

1 - Performance is steady state.

2- Construction is of sheet metal and parallel tube type.

3- There is no absorption of solar energy by a cover insofar which it affects losses from the collector.

4- Heat flow through the cover is one dimensional.

5- There is a negligible temperature drop through the cover.

6- The Cover is opaque to infrared radiation.

7- There is one dimensional heat flow through back insulation.

8- Temperature gradients around tubes can be neglected.

9- Dust and Dirt on the collector are negligible.

10- Pressure drops through tubes are negligible.

(f-chart method) has been used to find the optimum required solar collector area it is requiring a monthly average meteorological data which can be used to estimate the longterm thermal performance as a function of the major system design parameters [6].

$$
f=1.029 Y-0.065 X-0.245 Y^{2}+0.0018 X^{2}+0.0215 Y^{3}
$$

where $f$ is the fraction of the monthly total heating load (generator) supplied by solar energy and $\mathrm{X}, \mathrm{Y}$ are the two dimensionless groups.

$$
\begin{aligned}
& X=F_{R} U_{L} \times \frac{F_{R}^{\prime}}{F_{R}} \times\left(\bar{T}_{r e f}-\bar{T}_{a}\right) \times \Delta t \times \frac{A_{C}}{L} \\
& Y=F_{R}(\tau \alpha)_{n} \times \frac{F_{R}^{\prime}}{F_{R}} \times \frac{(\overline{\tau \alpha})}{(\tau \alpha)_{n}} \times \bar{H}_{T} N_{f} \times \frac{A_{C}}{L}
\end{aligned}
$$

The (f-chart method) has been generated for storage capacity of $75 \mathrm{~L}$ of stored water per square meter of collector area. f-chart can be used to estimate the performance of the system with other storage capacities by modifying the dimensionless group $\mathrm{X}$ by the storage size correction factor given in equation (4) [6] :

$$
\frac{X_{C}}{X}=\left(\frac{\text { Actual storage capacity }}{\text { standard storage capacity }}\right)^{-0.25}
$$

And the monthly total heating load (generator) supplied by solar energy given by equation:

$$
F_{L}=f \cdot Q_{L}
$$

To calculate the amount of auxiliary energy added to operate the system in the absence of solar radiation required for its operation using the following equation:

$$
Q_{\text {aux }}=(1-f) \times Q_{L}
$$

The optimum value of a solar collector tilt angle during summer [1] is: 
$\beta=(\varnothing-15)$

Where $\varnothing$ is the latitude angle and is equal $36^{\circ}$ for Mosul city.

And the useful energy collected in system solar collectors:

$$
Q_{u}=A_{c} F_{R}\left[S-U_{L}\left(T_{i}-T_{a}\right)\right]
$$

The collector overall heat loss (U) is the sum of the top (UT), back (Ub) and edge (Ue) heat loss coefficient it means that:

$$
U=U_{t}+U_{b}+U_{e}
$$

The collector heat removal factor $\left(F_{R}\right)$ is the ratio of useful heat obtained in collector to the heat collected by collector when the absorber surface temperature is equal to fluid entire temperature on every point of the collector surface[5].

$$
F_{R}=\frac{m^{\circ} C p}{A_{c} U_{L}}\left[1-\exp \left(-\frac{A_{c} U_{L} F^{\prime}}{m^{\circ} C_{P}}\right)\right]
$$

The instantaneous Thermal efficiency of the solar collectors is the ratio of useful energy obtained in collector to solar radiation incoming to it. It can be formulated as [7]:

$$
\eta=\frac{Q_{u}}{I_{T} A_{C}}
$$

Perfect mixing within the tank is assumed. if the rate of the heat addition and removal for a reasonable period of time $\Delta t$ are assumed to be constant, equation can be written for each time interval [5]:

$$
T_{s, \text { new }}=T_{s, \text { old }}+\frac{\Delta t_{s}}{m_{s} C_{P}}\left[Q_{u}-Q_{L}-(U A)_{s}\left(T_{s, \text { old }}-T_{a}\right)\right]
$$

The (f-chart method) needs a number of data input to the computer program as the basic requirements in the design of a solar collector, appropriate values for a properly designed collector values of $\left(F_{R} U_{L}\right)$ around $4 \mathrm{~W} / \mathrm{m}^{2} .{ }^{\circ} \mathrm{C}$ and $2.6 \mathrm{~W} / \mathrm{m}^{2} .{ }^{\circ} \mathrm{C}$ for one - and two glass covers, respectively, and 0.7 for $\left(F_{R}(\tau \alpha)_{n}\right)$. The ratio $\left(\mathrm{F}_{\mathrm{R}}^{\prime} / \mathrm{F}_{\mathrm{R}}\right)$ is the correction for various temperature drops between the collector and the storage tank. It can be calculated on the basis of heat-exchange performance. For a well design system this ratio should be about (0.95) [8]. The absorber plate is a black painted emissivity 0.15 and absorptivity 0.93 and it has 15 welded tubes of $0.01188 \mathrm{~m}$ diameter and all collectors unit facing south. The calculation of the solar collector and storage tank system proceed at an initial temperature of storage tank and inlet water temperature equal to the ambient temperature [1], and mean plate temperature equals $(\mathrm{Ta}+10)$ [6]. (UA) is taken as $11.1 \mathrm{~W} / \mathrm{K}$ [9]. The heating Load for generator QL is taken as zero at time when the tank temperature is below $88^{\circ} \mathrm{C}$. The temperature drop between the heat source and the generator is taken as $8^{\circ} \mathrm{C}$.

\section{Modeling of absorption system}

The system is modeled by treating each of the major components i.e. the generator, absorber, condenser, evaporator and solution heat exchanger as a single control volume. The heat addition and rejection at each component is obtained by taking an energy balance across each component. And the system is conditions:

1- The analysis is made under steady conditions. 
2- There is no departure of chemical substances from the cycle to the environment.

3- The kinetic and potential energy effects are neglected.

4- vapor flow rate generated in the generator equals vapor absorbed in absorber.

5- The refrigerant (water) at the outlet of the condenser is saturated liquid.

6- The refrigerant (water) at the outlet of the evaporator is saturated vapor.

7- Pressure losses in the pipelines and all heat exchangers are negligible.

8- Heat exchange between the system and surroundings is negligible

9- The system produce chilled water, and generator is driven by hot water.

10- The system rejects heat to cooling water at the condenser and absorber.

\section{The generator}

Considering the mass balance about generator:

$m_{7}^{\circ}=m_{1}^{\circ}+m_{8}^{\circ}$

$m_{7}^{\circ} X_{7}=m_{8}^{\circ} X_{8}$

By rearranging equations (13), (14):

$m_{8}^{\circ}=\frac{X_{7}}{X_{8}-X_{7}} m_{1}^{\circ}$

The mass flow rate of refrigerant is obtained by energy balance at evaporator and is given as follows:

$m_{3}^{\circ}=Q_{e} /\left(h_{4}-h_{3}\right)$

The rate of heat addition in the generator is the energy input to the cycle is given by the following equation:

$$
\begin{aligned}
& T_{\mathrm{g}}=T_{8} \\
& Q_{g}=m_{1}^{\circ} h_{1}+m_{8}^{\circ} h_{8}-m_{7}^{\circ} h_{7}
\end{aligned}
$$

\section{The absorber}

The mass balance about absorber

$$
m_{5}^{\circ}=m_{4}^{\circ}+m_{10}^{\circ}
$$

$m_{5}^{\circ} X_{5}=m_{10}^{\circ} X_{10}$

By rearranging equations (19), (20):

$$
\begin{aligned}
& m_{5}^{\circ} \\
& =\frac{X_{10}}{X_{10}-X_{5}} m_{4}^{\circ}
\end{aligned}
$$

The rate of heat rejection by absorber is given by the following equation:

$T_{a}=T_{5}$

$Q_{a}=m_{4}^{\circ} h_{4}+m_{10}^{\circ} h_{10}-m_{5}^{\circ} h_{5}$

\section{The condenser}

The rate of sensible heat rejection out of the condenser is given by this equation:

$$
Q_{c, \overline{1}}=m_{1}^{\circ}\left(h_{1}-h_{\overline{2}}\right)
$$

The rate of latent heat rejection out of the condenser is:

$$
Q_{c, \overline{2}}=m_{1}^{\circ}\left(h_{\overline{2}}-h_{3}\right)
$$

The rate of heat rejection out of the condenser is given by the following equations: 


$$
Q_{c}=Q_{c, \overline{1}}+Q_{c, \overline{2}}
$$

\section{The evaporator}

The rate of absorption in the evaporator is given by the following equation:

$Q_{e}=m_{4}^{\circ}\left(h_{4}-h_{3}\right)$

\section{The solution heat exchanger}

The expression for the effectiveness is given as:

$E=\frac{T_{8}-T_{9}}{T_{8}-T_{6}}$

Rearranging equation (28),

$T_{9}=T_{8}-E\left(T_{8}-T_{9}\right)$

An energy balance on the hot side of the solution heat exchanger is given by the following equation:

$$
Q_{h x, h}=m_{8}^{\circ} C p_{8}\left(T_{8}-T_{9}\right)
$$

Similarly an energy balance on the cold side of the solution heat exchanger is given by the following equation:

$$
Q_{h x, c o}=m_{6}^{\circ} C p_{6}\left(T_{7}-T_{6}\right)
$$

Overall energy balance on the solution heat exchanger is satisfied:

$Q_{h x, h}=Q_{h x, c o}$

\section{The coefficient of performance}

The overall energy balance equation for the whole cycle will be:

$$
Q_{g}+Q_{e}-Q_{c}-Q_{a}=0
$$

The COP for the system is usually defined as:

$$
C O P=\frac{Q_{e}}{Q_{g}}
$$

Simulation is carried out for a constant refrigeration capacity $7.12 \mathrm{~kW}$. For tow shell absorption cooling system and all heat exchangers being an even multiple tube passes except solution heat exchanger which is a double tube heat exchanger. The generator temperature is varied from $65^{\circ} \mathrm{C}$ to $90^{\circ} \mathrm{C}$, the absorber temperature is varied from $35^{\circ} \mathrm{C}$ to $45^{\circ} \mathrm{C}$, the condenser temperature is varied from $40^{\circ} \mathrm{C}$ to $50^{\circ} \mathrm{C}$, the evaporator temperature is varied from $4^{\circ} \mathrm{C}$ to $12^{\circ} \mathrm{C}$ and the effectiveness solution heat exchanger is varied from 0.5 to 0.9 .in this analysis, the thermal - physical properties of working fluid have to be known as analytic function and for thermodynamic analysis of the absorption system the principle of mass conservation and firs law of thermodynamic are applied to each component of the system .And "Successive Substitution " [10] has been used to perform the simulation.

\section{Results and Discussion}

The computer program has been used to model and simulate of a solar system to obtain the optimum area and design of a solar collector units, number of collector covers and the storage tank volume with respect to the weather data of Mosul city.

Figure 5 which show the variation of the number of flat plate solar collector units during May versus the generator temperature, it can be seen that the optimum generator temperature for which the number of flat plat solar collector units is minimum. This 
optimum generator temperature corresponds to generator temperature giving the maximum COP. And figure 6 shows the variation of the value of solar fraction with respect to the months which absorption system works during them, it can be seen when using the solar collector with tow cover can provide a larger amount of solar energy instead of a single cover solar collector.

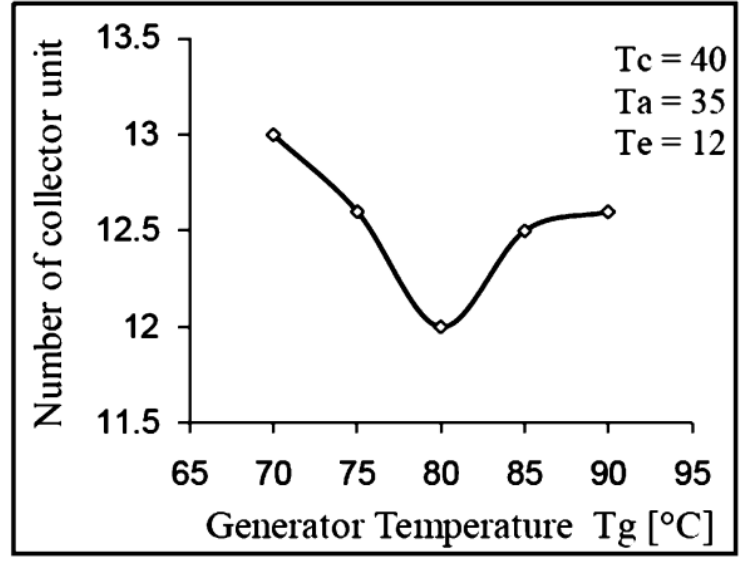

Fig (5): Variation of the number of solar collector units versus generator temperature.

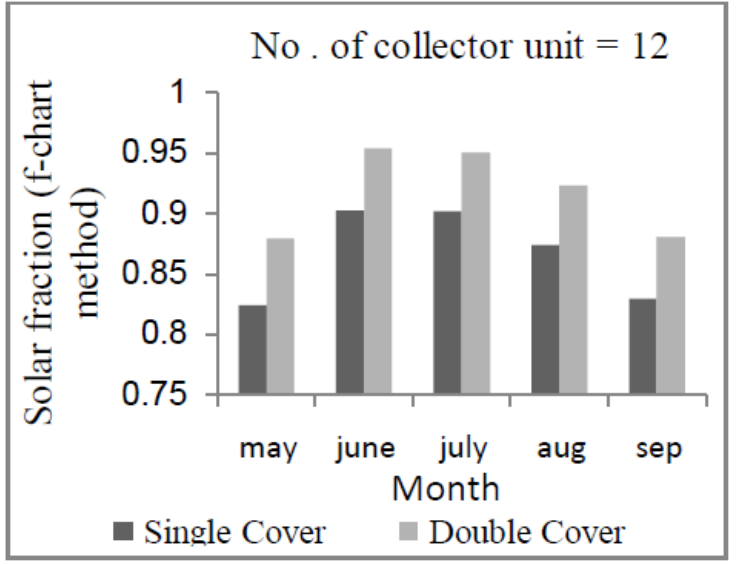

Fig(6) : Variation of the value of solar fraction versus the months which absorption system working during them in the case of using single cover or a double cover

Figure 7 shows the variation of solar fraction versus the number of solar collector units, it can be seen that the value of solar fraction is equal to 0.87 at using a solar collector with an area of $26 \mathrm{~m}^{2}$ while the value of solar fraction reach to 0.96 at using collector area of $30 \mathrm{~m}^{2}$, and the previous value of 0.87 is more acceptable in economic aspect; because the system needs to additional heat to provide the temperature required to work the system when a solar collectors do not provide a specified temperature for the work of the system; so the system needs to add the heat by the auxiliary heater, especially in the early hours of the day as well as in the days where the cloudy or dirt stormy weather. Figure 8 shows the decreasing in the value of heat added by auxiliary heater with increasing a number of collector units.

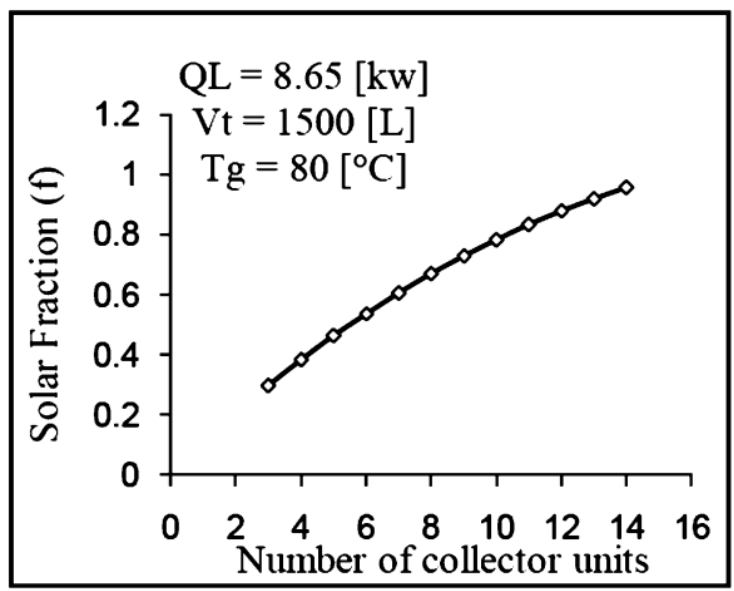

Fig (7): Variation of solar fraction versus number of flat plate solar collector units.

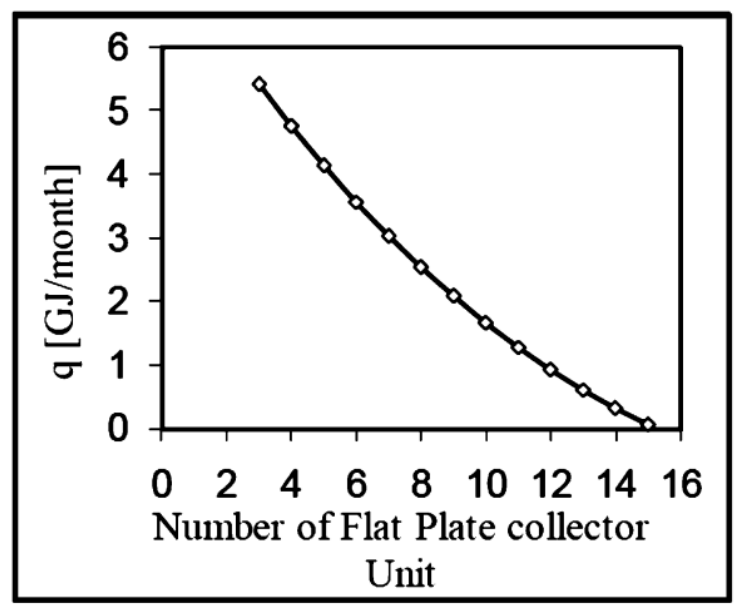

Fig (8): Variation of heat added by auxiliary heater with a number of collector units. 
Figure 9 shows the instantaneous thermal collector efficiency as a function of time for a monthly average day of July, it is clear that the solar collector operates at higher efficiency in the morning and with increasing mean plate temperature, the actual useful heat gain decreases while the system losses increases.

A computer model has been built up to study the effect of internal operation conditions on the COP of the absorption cooling system to find the optimum internal operation conditions that given the maximum value of the COP. Figures (10), (11) and (12) illustrate the relationship between the system coefficient of performance and the generator

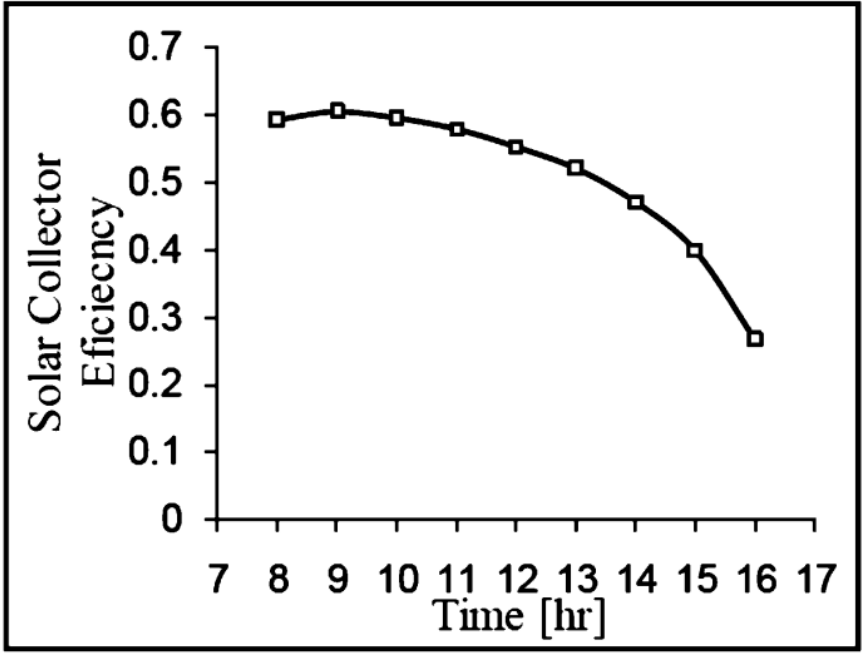

Fig(9) : the instantaneous thermal collector efficiency as a function of time for a monthly average day of July

temperature at a different system temperatures. These figures show that the pattern at which COP depends on the generator temperature are always the same. However, it's the value that changes with system's changing temperatures. It's noticed that for every specified system settings, there exits a lower boundary of the generator's temperature below which the absorption system will not operate. Above this temperature limit, as the generator temperature increase the coefficient of performance of the system increases sharply until generator's temperature reaches $80^{\circ} \mathrm{C}$ and the system COP reaches a maximum value which equals 0.8228 and decreases slightly after up to the crystallization point. These figures indicate that the increasing in evaporator temperature leads to a rise in system COP from 0.754 to 0.8228 at a rate of $9.12 \%$ in the case of increasing the evaporator temperature from $6^{\circ} \mathrm{C}$ to $12^{\circ} \mathrm{C}$ when the generator temperature equals $80^{\circ} \mathrm{C}$. While increasing the absorber and condenser temperatures cause decrease in the system COP. As shown in Figure 13 that the rate of increase in the system COP is $18.3 \%$ in the case of the use of solution heat exchanger efficiency effectiveness which equals 0.8 from without using it.

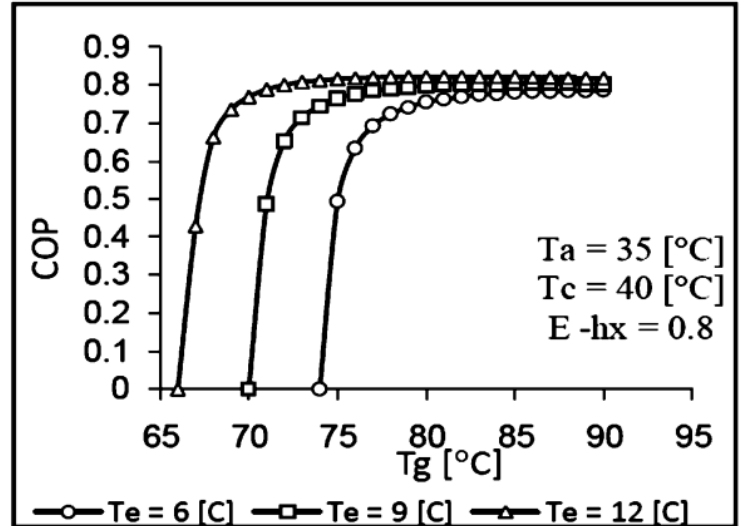

Fig(10): The variation of the system COP versus generator temperature at different evaporator temperatures

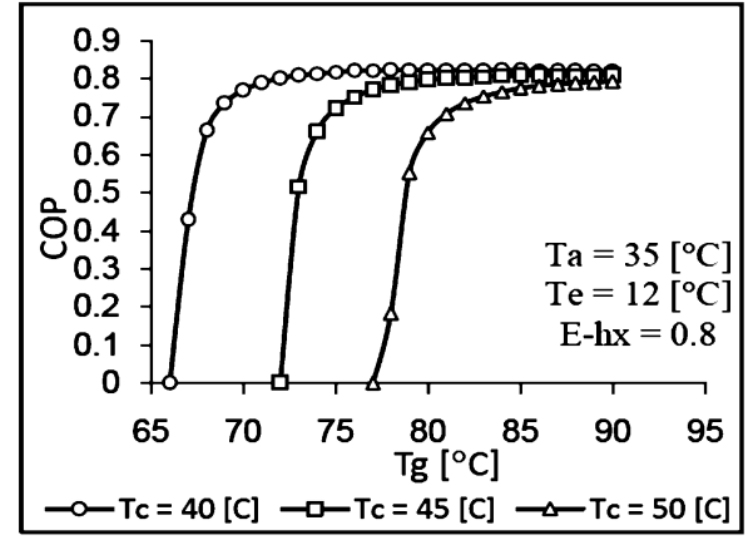

Fig (11): The variation of the system COP versus generator temperature at different condenser temperatures. 


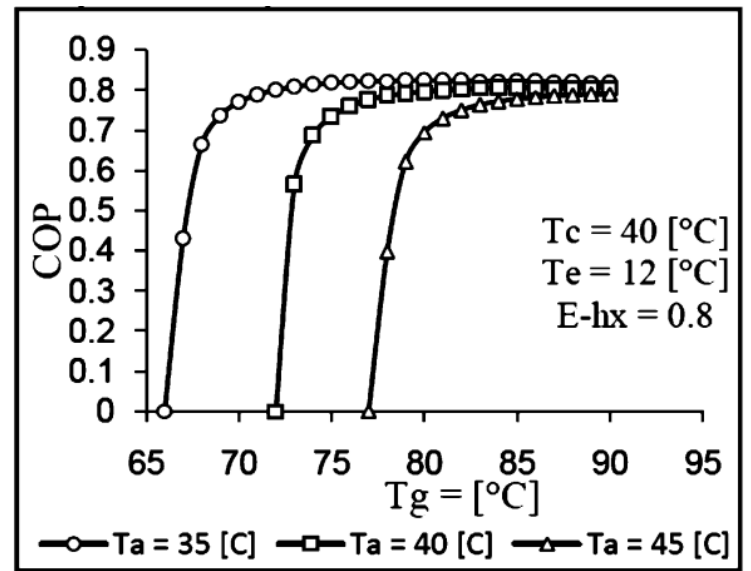

Fig (12): The variation of the system COP versus generator temperature at different absorber temperatures.

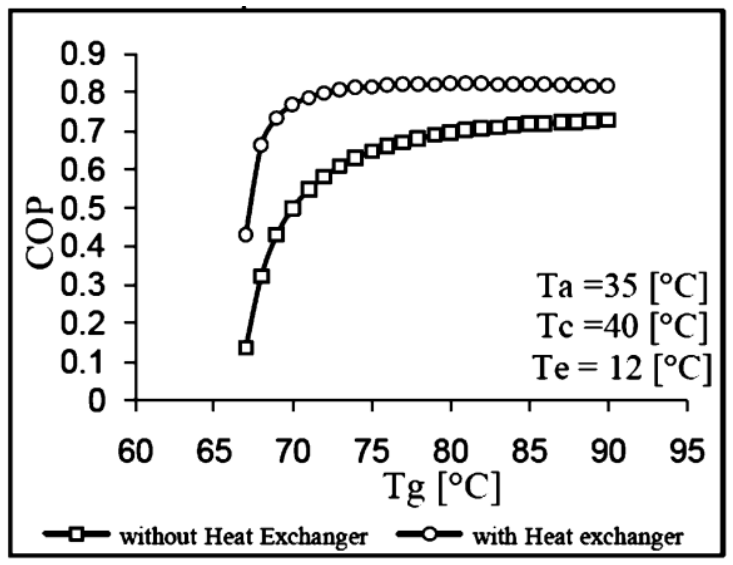

Fig (13): The variation of the system COP versus generator temperature with use solution heat exchanger and without use.

Figure 14 describes the effect of the generator temperature on its surface area. It can be seen that the increasing in the generator temperature leads to the decreasing of its surface area. This is a result from of the decreasing in the heat rate of delivered by the generator, and from the increasing of logarithmic mean temperature difference. And figure 15 shows the effect of the hot water temperature that inlet to the generator to the heat supplied to it at a different mass flow rates of water that inlet to the generator. It can be seen that the increasing in this temperature and mass flow rate of hot water result in the increase of Heat supplied to the generator.

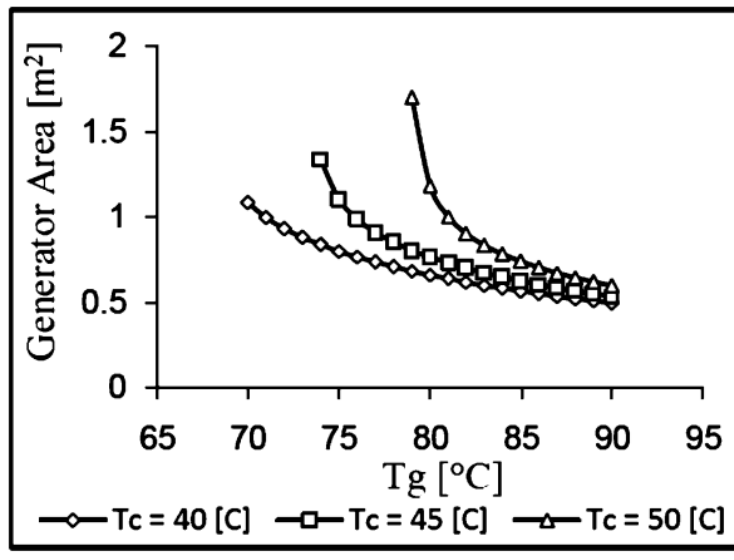

Fig (14): effect of the generator temperature on its surface area.

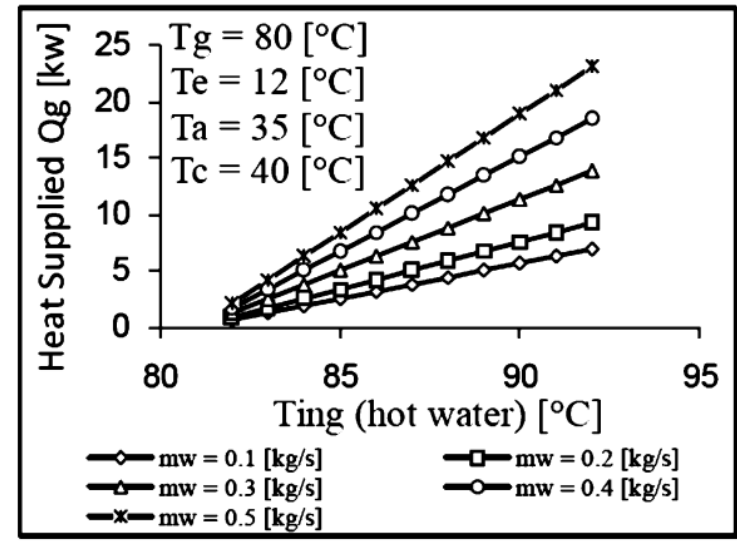

Fig(15): effect of hot water inlet temperature on the heat supplied to the generator

Figure 16 depicts the effect of the generator temperature on the surface area of absorber at different evaporator temperatures. It can be seen that increase in the generator temperature lead to decrease of absorber surface area. Since the generator temperature affect on the inlet solution temperature which enter to the absorber leading to decrease the amount of heat generated in the absorber, which further resulted in the increase of 
logarithmic mean temperature difference in the absorber and solution heat exchanger. And figure 17 which show the effect of the cooling water inlet temperature to the absorber on the heat rejected from it at different mass flow rates of water inlet to the absorber. It can be seen that increase in this temperature lead to decrease of heat rejected from absorber, but increasing the mass flow rate of cooling water results in the increase of Heat reject from absorber.

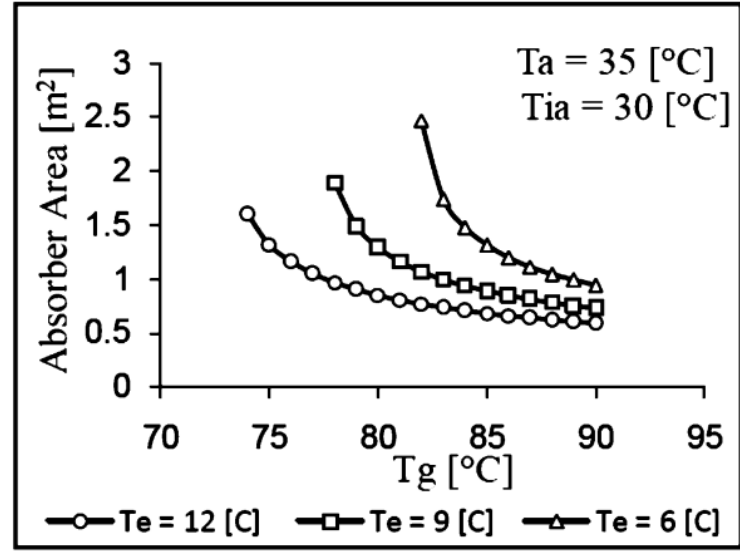

Fig (16): effect of the generator temperature on the absorber surface area.

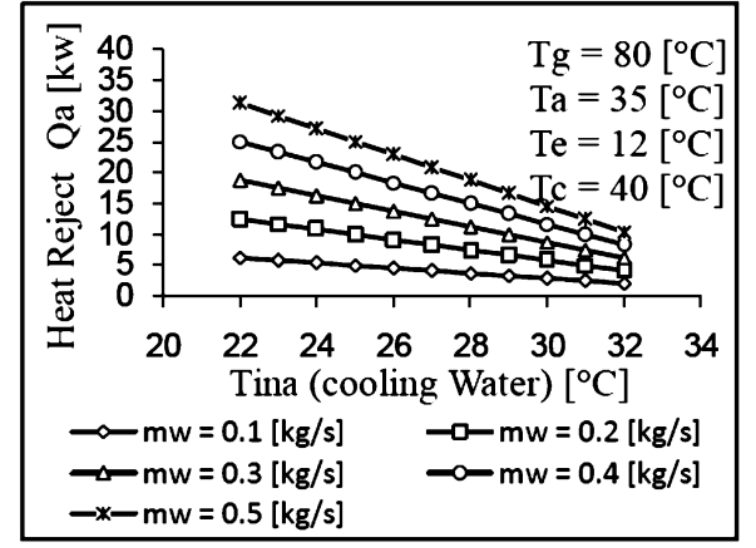

Fig(17):effect of cooling water temperature inlet to absorber on the heat rejected from it

Figure 18 illustrate the relation between the generator temperature and the evaporator surface area for different condenser temperatures. It can be seen that the evaporator area is independent of the generator temperature and is a function of the evaporator temperature only. And figure 19 illustrate too the relation between the generator temperature and the solution heat exchanger area at a different heat exchanger effectiveness. It can be seen that increase in this temperature lead to decrease the solution heat exchanger area, but increasing heat exchanger effectiveness results in the increase of

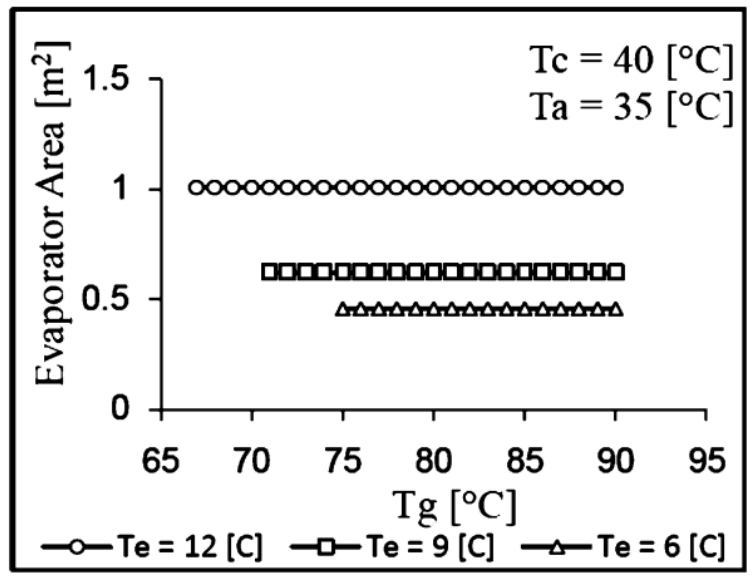

Fig (18): effect of the generator temperature on the evaporator surface area.

the solution heat exchanger area.

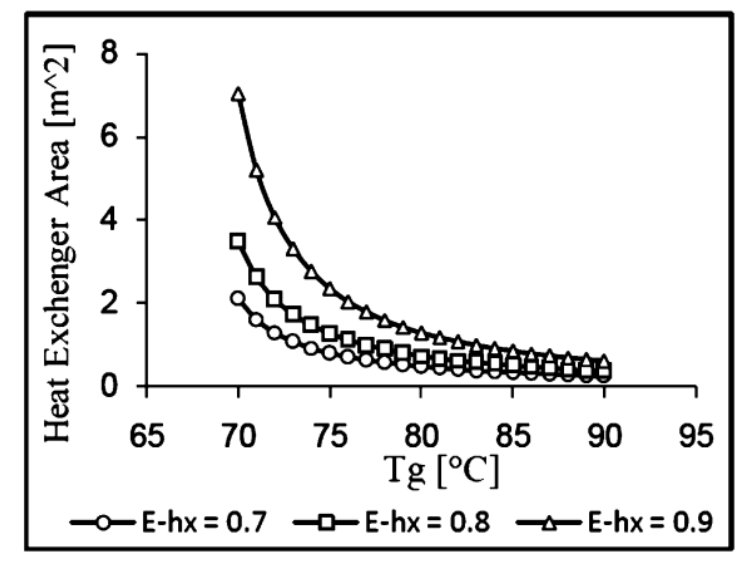

Fig (19): effect of the generator temperature on the solution heat exchanger surface area.

Figure 20 depicts the effect of the cooling water inlet temperature to the condenser on a surface area of it, when the condenser and absorber connecting by series connect (i.e., the 
cooling water exits from the absorber enters to the condenser to cool it), while the parallel connects means (the condenser and the absorber are cooling independently). It can be seen that a parallel connect result in the decrease of the condenser area. And figure 21 illustrate the effect of absorber tube length on the Heat reject from it at different tube diameters. It can be seen that increase in the tube length result in the increase of heat reject from the absorber.

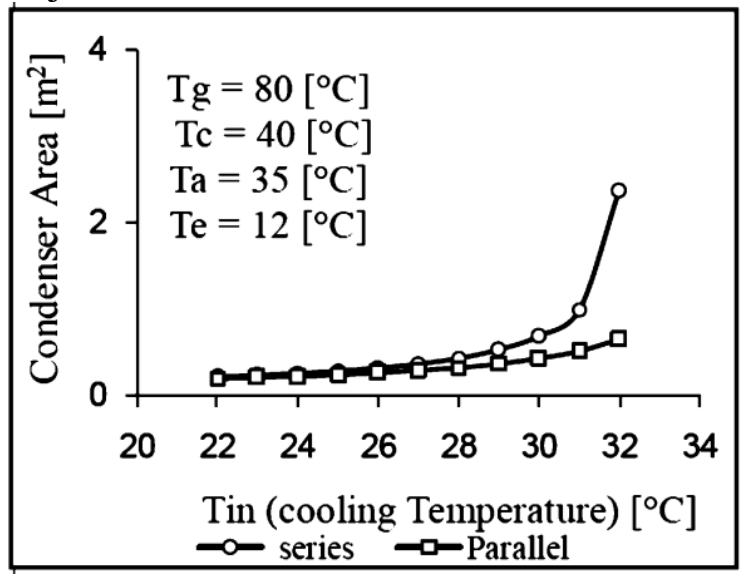

Fig (20): effect of the cooling water inlet temperature to condenser on the surface area of it.

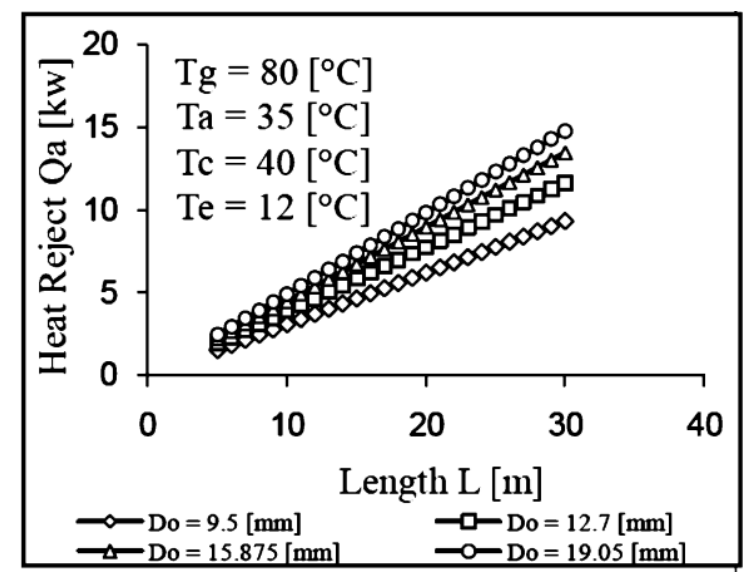

Fig (21): effect of the absorber tube length on the heat reject from it.

\section{Conclusions}

This research has been done to study the combined system consisting of a flat plate solar collector system with a single effect lithium bromide absorption cooling system. After getting the results it was concluded the following:

1- Getting a larger a mount of thermal energy provided by a solar in the case of use of double covers flat plate solar collector instead of one cover.

2- Area of a solar collector has a greatly affects on the amount of heat gain from solar collector, as well as the amount of heat supplied by auxiliary heater.

3- Solar collector area $26 \mathrm{~m}^{2}$ is sufficient to operate absorption system more than eight hour by using water storage tank with a capacity of $1500 \mathrm{~L}$ and depending on weather data of Mosul city.

4- The generator temperature $\left(80^{\circ} \mathrm{C}\right)$ gives the minimum number of solar collector units, this optimum generator temperature corresponds to generator temperature giving the maximum COP, when the condenser temperature is $40^{\circ} \mathrm{C}$, the absorber temperature is $35^{\circ} \mathrm{C}$ and the evaporator temperature equals $12^{\circ} \mathrm{C}$.

5- The generator temperature has a greatly affects on the absorption system COP.

6- The system COP increases by decreasing the condenser and evaporator temperatures.

7- The system COP increase by increasing the evaporator temperature.

8- The solution heat exchanger which is placed between the generator and absorber increase the system COP significantly.

9- a parallel connect between the absorber and the condenser result in the decrease of the condenser area. 


\section{References:}

1- Ghaddar N.K., Shihab M. and Bdeir F. " Modeling and Simulation of Solar Absorption System Performance in Beirut ". Renewable energy, Vol.10,No.4,pp.539-558,1997.

2- Hammad M. and Zurigat Y. " Performance of a Second Generation Solar Cooling Unit",. Solar energy ., Vol.62, No.2, pp.79-84 ,. 1998.

3- Alva .L.H and Gonzalez .J.E .,"Simulation of an Air-Cooled Solar Assisted Absorption Air Conditioning System", Proceeding of forum 2001, solar energy : the power to choose April 21-52, 2001 Washington, DC.

4- Florides G.A. , Kalogirou ,S.A. , Tassou, S.A . and Wrobel L.C. " Modeling and Simulation of an Absorption Solar Cooling System for Cyprus" ,. Solar energy ., Vol.72 . No. 1 , pp. $43-51,2002$.

5- Duffie , J.A. and Beckman ,W.A., “ Solar Engineering of Thermal Process", Wisconsin , John Wiley \& Sons., 1991.

6- Duffie , J.A., Beckman ,W.A., and Klein , S . A ., “ Solar Heating Design by F-chart method", Wisconsin, John Wiley \& Sons., 1977.

7- Lunde ,P.J., “ Solar thermal engineering ” John Wiley \& Sons., New York, 1980.

8- Suryanarayana . N.V " Design and Simulation of Thermal System" McGraw - Hill book company ., New York, 2003.

9- Mittal .V ., Kasana . K.S ., Thkur . N.S ., "Modeling and Simulation of Solar Absorption cooling System For India"., Journal of energy in south Africa . Vol 17 No 3 . August 2006.

10- Stocker ,W.F, "Design of Thermal System" ,Mc .Graw - Hill. 